\title{
LEITURA E FORMAÇÃO: CONTRIBUIÇÕES DA BIBLIOTECA NO RIO ARAPIUNS-ALDEIA NOVA VISTA
}

Luanna Cardoso Oliveira Zair Henrique Santos

RESUMO: Este artigo relata uma pesquisa-ação que teve como objetivo investigar como a circulação de leitura se manifesta, e se ocorre de modo participativo ou não, entre os cidadãos de uma comunidade indígena. A metodologia é baseada em Franco (2005;2010;2016), e as espirais cíclicas: planejamento; ação; reflexão, que possibilitam uma reformulação das ações sempre que necessário, analisando o objeto e o processo da pesquisa continuamente. São utilizados como ancoragem teórica: Britto (2003, 2015a, 2015b); Candido (2011); Santos (2016); Saviani e Duarte (2010). Os resultados demonstram que há significativa circulação de leitura e livros na aldeia a partir da organização da biblioteca escolar; as ações de leitura têm contribuído para o aperfeiçoamento da leitura dos estudantes. Entretanto, a participação da comunidade ainda é tímida e indireta, assim como de parte do corpo docente, em suma, as pessoas da comunidade ainda não assumem a biblioteca na sua totalidade.

PALAVRAS-CHAVE: Educação. Leitura. Literatura. Biblioteca. Indígena.

\section{INTRODUÇÃo}

A pesquisa intitulada Leitura e formação: contribuições da biblioteca no rio Arapiuns-aldeia Nova Vista foi desenvolvida no Programa de Pós-Graduação em Educação da Universidade Federal do Oeste do Pará -Ufopa. Está vinculada ao Grupo de Estudos Leitura e Intervenção em Literatura Infantil e Juvenil na Escola1-Lelit ${ }^{1}$ que se divide em várias ações, entre estas, o projeto Entre o compromisso e a realidade: Levar a ler a lugares distantes, que busca constituir ou revitalizar bibliotecas escolares ou comunitárias, até o momento já foram desenvolvidos doze trabalhos na região Oeste do Pará. Este texto traz um relato das atividades e reflexões desenvolvidas na supracitada pesquisa.

A construção de bibliotecas em lugares distantes representam muito mais que um espaço de entretenimento e slogans clichês como: "ler para viajar", "leitura por prazer", "hábito da leitura", "gosto pela leitura", que inúmeras campanhas e projetos têm difundido nos últimos anos, atribuindo suas ações a um caráter assistencialista, reforçando uma concepção ingênua de leitura (BRITTO, 2003).

Levar a ler e lugares distantes são expressões utilizadas por Santos (2016). O primeiro termo consiste em identificar ações de intervenção de caráter político, pedagógico e cultural, extrapolando atividades genéricas de incentivo e promoção de leitura. A distância que se menciona, não é apenas geográfica, mas sobretudo, a que se constitui na relação social, embora haja especificidades culturais da aldeia, esta aproxima-se da periferia de grandes centros urbanos que não têm direitos fundamentais respeitados. Especificamente para região e comunidade pesquisada, essa relação tende a ser tensa e conflituosa do ponto de vista das identidades e toda a negação histórica à qual foram postos, o que permite afirmar que estão ainda mais distantes.

Por que propor livros e leitura a comunidade indígena?

Primeiramente, livros, leitura e biblioteca, são produções humanas, o fato de a classe dominante se apropriar de boa parte dos conhecimentos artísticos, culturais e científicos transformando-os em propriedade/mercadoria não significa que sejam intrínsecos a ela. Apropriar-se dessas objetivações implica interação cultural, isso vale para leitura, entendida como possibilidade de

1 O grupo reúne professores e estudantes de Letras e Pedagogia da Ufopa, de graduação, pós-graduação e professores de ensino básico de Santarém, para atividades de estudos, formação e intervenção pedagógica em literatura, alfabetização e biblioteca. 
cidadania. Para os moradores da aldeia Nova Vista, livros e leitura podem contribuir para formação intelectual, social, cultural, política e também para maior comprometimento social.

\title{
LEITURA: CONHECIMENTO E FORMAÇÃo
}

Que a leitura é necessária para a sociedade e que muito tem se falado sobre o assunto nas últimas décadas, não parece novidade. Contudo, a falta de reflexões agudas e a busca de fórmulas milagrosas, aceleradas pela força do lucro acabou criando estereótipos banais sobre a leitura que não correspondem à realidade, mas que são anunciados com facilidades e vão penetrando no mundo escolar e na sociedade em geral como verdades: "método eficaz de alfabetização"; "leitura rápida"; "leitura dinâmica", etc.

Fala-se de "leitura de mundo", "leitura de imagem", "leitura e direito", para Britto (2015b, p. 25), há um equívoco nesse uso infracional do conceito de leitura. Para esse autor:

O vocábulo leitura no seu sentido básico corresponde à decifração e à intelecção de signos gráficos que representam a linguagem oral, estando as duas ações básicas de ler enunciadas nessa definição - decifrar e entender - de tal modo interligadas que uma implica a outra.

A leitura, portanto, não se restringe à decodificação, implicando a compreensão, a busca de significações. Desse modo, ensinar a leitura perpassa por contextualizar os signos, atribuindo significados sociais para o que se lê. A leitura, no seu aspecto formativo, possibilita a intervenção no/sobre o mundo e a compreensão das contradições nele presente. Quando se realiza a leitura nessa perspectiva, o ato de ler assume função política, crítica e emancipadora, a qual instiga o leitor a transformar a realidade.

\begin{abstract}
A leitura crítica possibilitaria à pessoa um projeto de transformação social que combate a naturalização da barbárie, uma vez que lhe daria condições de entender as contradições da sociedade conservadora, em que poucos detêm o poder e usufruem dos privilégios, enquanto a maioria é sistematicamente ferida em seus direitos fundamentais. Além disso, a leitura crítica armaria a sociedade para abalar o mundo das certezas através de questionamentos, desmascarando o funcionamento das ideologias alienantes. As pessoas passariam a entender o porquê de as propagandas do Estado incentivarem o consumismo, assim como exaltarem a docilidade, a ingenuidade e a cordialidade do homem. (SANTOS, 2016, p.31)
\end{abstract}

Sendo a leitura-escrita um elemento cultural através do qual se cristaliza a história das gerações precedentes, ao lermos, nos apropriamos e interagimos com a ideia alheia e, a partir disso, formamos conceitos, participamos socialmente e, quanto mais participarmos, maiores as necessidades de criar, imaginar e produzir sentidos. Essas experiências com a cultura proporcionam o desenvolvimento das máximas qualidades humanas, visto que:

A língua que falamos, os valores, os sentimentos, os hábitos, o gosto, a religião ou as crenças e os conhecimentos que incorporamos não são realidades naturais, mas uma produção histórica. São os seres humanos em sociedade que produzem as condições que se expressam no seu modo de pensar, sentir e de ser. (FRIGOTTO, 2012, p.267-268)

Dessa forma, o homem desenvolve cada vez mais aptidões para imaginar, criar, interagir e desenvolver-se, vivendo a possibilidade da formação Omnilateral.

Omnilateral é um termo que vem do latim e cuja tradução literal significa "todos os lados ou dimensões". Educação omnilateral significa, assim, a concepção de educação 
ou de formação humana que busca levar em conta todas as dimensões que constituem a especificidade do ser humano e as condições objetivas e subjetivas reais para seu pleno desenvolvimento histórico. (FRIGOTTO, 2012, p. 267)

A apropriação dos elementos culturais são subsídios à continuação das novas gerações e, principalmente, à formação do gênero humano. Tais características não são transmitidas pela herança genética, como acontece com outras espécies; faz-se necessário a apropriação dos elementos culturais, dos valores, da linguagem e do conhecimento acumulado historicamente para que o processo de humanização se efetue. Quanto a isso Duarte (2016, p. 37), enfatiza que:

As características do gênero humano não são, porém, transmitidas pela herança genética, porque não se acumulam no organismo humano. As características do gênero humano foram criadas e desenvolvidas ao longo do processo histórico de apropriação da natureza pela atividade social e de objetivação dos seres humanos na natureza transformada.

Sobre a importância da apropriação dos objetos sociais na formação humana Saviani e Duarte (2010), analisando os Manuscritos econômicos filosóficos de 1844, de Karl Marx, observam que:

Ocorre que não há outra maneira de o indivíduo humano se formar e se desenvolver como ser genérico senão pela dialética entre a apropriação da atividade humana objetivada no mundo da cultura (aqui entendida como tudo aquilo que o ser humano produz em termos materiais e não materiais) e a objetivação da individualidade por meio da atividade vital, isto é, do trabalho. (p.426)

Assumir a leitura como prática social é desvinculá-la de uma ideologia que sustenta ler como um dom, que nascemos predisposto a isto e que qualquer um, em quaisquer circunstâncias, pode ser leitor. "Na verdade, o problema, para a maioria, é não poder ler - seja porque não dispõe de condições objetivas (tempo, lugar, material apropriado) seja porque não dispõe de condições subjetivas (conhecimento, competência, formação)”. (BRITTO, 2015b, p.36)

Em consonância com esse argumento, Silva (2005, p. 21), afirma que "o ato de ler para se efetivar, necessita do preenchimento de determinadas condições do contexto social". Lê quem tem tempo: em uma sociedade baseada em um sistema que explora os homens com longas jornadas de trabalho e salário indigno, só lhes resta o cansaço ao fim do dia e o dinheiro para sobreviver; lê quem possui condições materiais: livros são caros, em muitos lugares não há biblioteca, alguns não têm recursos para deslocar-se semanalmente para emprestar livros; lê quem tem condições subjetivas: conhecimento prévio, referências, experiências culturais.

O trabalhador com salário mínimo, jornada de trabalho longa, está ao final do dia exausto para desfrutar de um bom livro, mesmo que este livro possibilite conscientização e ele se esforce para compreendê-lo. As funções mecânicas que o trabalhador desenvolve não exigem esforço intelectual que venha a criar necessidades elevadas de conhecimento; o trabalho alienado que consome seu tempo e liberdade não permite a apropriação plena da essência humana, negando-lhe formação íntegra.

O trabalhador aliena-se de seu trabalho porque é obrigado a vender sua atividade em troca de um salário que lhe assegure a sobrevivência. Isso quer dizer que, para poder continuar a viver, o trabalhador deve vender uma parte de sua vida e, mais do que isso, vender a parte mais importante de sua vida, que é a atividade por meio da qual ele poderia formar-se, fazendo da essência humana, isto é, das potências essenciais humanas 
formadas historicamente, a essência de sua individualidade. (SAVIANI E DUARTE, 2010, p. 429)

Compreender a leitura como ato político vai na contramão de concepções ingênuas, as quais entendem leitura como ações superficiais para preencher o tempo dos alunos, cumprimento de atividades simplórias com fins escolares (responder questões que exigem o mínimo de esforço intelectual). A leitura na escola é dada como atividade reprodutora e repetitiva. É necessário o mergulho aprofundado nos textos, com estratégias que instiguem o pensamento, a busca de significados e inter-relações com o mundo; são imprescindíveis experiências leitoras de variedades de gêneros, para que o leitor tenha aprofundamento sobre o mundo e sobre si. "Ler, não é chato nem fácil, é difícil" como ensina Britto (2015b).

Ler, para além do que já somos, ler como experiência e possibilidade de por ela se modificar, supõe a posse de conhecimentos que muitas vezes não são de domínio imediato, exigindo desprendimento, abertura, determinação, disciplina. Sem disposição para ler e sem a compreensão do que seja literatura, a pessoa rapidamente passa a acreditar que tal livro é chato e que a história não prende a atenção e que o autor está enrolando. Se o que se busca é promover a leitura como valor, é imperativo encontrar estratégias mais densas e mais fundamentadas de estimular a leitura, reconhecendo que ler, em muitas situações, é difícil e que a satisfação que daí se pode retirar é de natureza muito distinta da que oferece o entretenimento cotidiano. (BRITTO, 2015b, p.31).

Na mesma direção Castrillón (2011b) faz um alerta sobre a tarefa de ler, critica as instituições que difundem a leitura como atividade cujo o fim único é o prazer, desassociando esta tarefa da complexidade e esforço que exige:

Não se pode negar o prazer que a leitura produz em uma pessoa que superou a dificulda-
de de tornar-se leitor, ou melhor, que supera diariamente o enfrentamento com um texto
considerado complexo. Porém, o prazer como prerrogativa para atrair a leitura é um dos
lugares-comuns mais cristalizados nas instituições em que a leitura e a escrita deveriam
ser preocupação central: a escola e a biblioteca. E esta, ou é uma ordem demagógica que
pretende destituir a leitura de toda dificuldade e oferecer a possibilidade de acessá-la sem
esforço; ou, de fato, destitui-se, com isso, a leitura de sentido que se pode ter na busca
pelo significado e se apresenta como uma mercadoria, um bem de consumo, um meio
para a evasão, em que a intermediação da escola não faria falta. (CASTRILLON, 2011b,
p.02)

Para Benedito Nunes (1996, p. 193), "a prática da leitura seria um adestramento reflexivo, um exercício de conhecimento do mundo, de nós mesmo e dos outros". Embora, aparentemente haja interesse de difundir a leitura em nosso país, o intuito da maioria das promoções de leitura, mesmo quando não se tem consciência disso, não é instigar as pessoas a pensarem criticamente, a buscar formação intelectual, social e política, ao contrário, há uma compreensão distorcida de leitura, predominantemente difunde-se a ideia de buscar prazer ou vagar por mundos inimagináveis, quando tais experiências deveriam proporcionar percepção crítica e compreensão do porquê que as coisas são como são.

Aprender a ler e a escrever só faz sentido se for para ampliar a intervenção do sujeito no mundo, principalmente pela autoconsciência, que não é só subjetiva e individual. Não é eu e eu, mas eu sou eu, neste lugar, com estas pessoas e reconheço as relações históricas, culturais, políticas envolvidas na sua condição de ser e nas condições de realização do contexto histórico. É isto que ele chama de conscientização. (SANTOS, 2016, p.29) 
Para Zilberman (1983, p. 43) "a leitura, quando inserida no processo social, renuncia a qualquer tipo de neutralidade”. Portanto, ao entender leitura como ato político e formativo, há que romper com a ideia de leitura mecânica, assistencialista. "O ensino da leitura e da escrita já não é a repetição mecânica de ba-be-bi-bo-bu nem a memorização de uma palavra alienada, mas a difícil aprendizagem de "nomear o mundo" (FREIRE, 1976, p.48).

$\mathrm{O}$ ato de ler não salva o homem das mazelas do mundo, o leitor não é alguém isento a erros, curioso ao extremo, que tem resposta para tudo. Entretanto, a leitura possibilita refletir, entender a sociedade, podendo a pessoa intervir e participar socialmente. Embora a oralidade seja uma marca da nossa cultura, a comunicação não está restrita a ela, através da escrita se cristaliza e possibilita que outras gerações acessem o conhecimento, a história, a política, de determinada época e sociedade. No entanto, para que se efetive o desenvolvimento completo formação omnilateral -, é imprescindível uma ordem justa, que garanta a equidade de direitos e uma educação que não seja privilégio de alguns, mas direito de todos.

\section{A formação pela literatura}

Como e por que a leitura, principalmente a do texto literário, pode se constituir fator de liberdade e transformação dos leitores? Primeiramente, é importante questionar o que seria leitor. Para Britto (2015a), circula no debate e no senso comum uma vaga ideia de leitor como alguém que está sempre com livro à mão pensando na vida e desbravando mares nunca dantes navegados.

Esta vaga ideia de leitor - característica da perspectiva mítico-salvacionista tão presente no discurso pedagógico - liberal não incorpora as indagações mais fortes de cultura, de conhecimento e de política, não avança para além da afirmação de que ler é cultura, instrução, descoberta, viagem, etc. E é preciso que assim seja, para que haja coincidência entre a concepção de leitor e a também vaga noção de participação social: o leitor "crítico" assim porque, informado pelos meios de comunicação de massa- formadores de opinião -mantém-se na lógica liberal de democracia formal. (BRITTO, 2015a, p.65)

Compreende-se que a ideia de leitor está inter-relacionado com a concepção de leitura que prevalece no senso comum, pautada no prazer e no gostoso, descolando-se da leitura como prática social que exige condições concretas para se realizar, que sob uma ótica formativa e política possibilita ao leitor a indagação, um posicionamento no mundo, sendo, portanto, tarefa difícil e exigente. O leitor é considerado aquele sujeito motivado pela infinita curiosidade, com óculos sob o nariz que em hipótese nenhuma se descola do livro (um modelo abstrato), mítico e não o sujeito que usa a leitura, a escrita para intervir na sociedade, na política etc.

Sobre os objetivos da formação do leitor literário Colomer (2007), afirma:

O objetivo da educação literária é, em primeiro lugar, o de contribuir para a formação da pessoa, uma formação ligada indissoluvelmente à construção da sociabilidade e realizada através da confrontação com textos que explicitam a forma em que as gerações anteriores e as contemporâneas abordam a avaliação da atividade humana através da linguagem. Em segundo lugar o confronto entre textos literários distintos oferece ao aluno a ocasião de enfrentar a diversidade cultural e social (...). Em terceiro lugar, o ensino da literatura pode reformular a antiga justificativa sobre idoneidade na formação linguística. (p.31-32) 
Silva (1991, p. 23) afirma que, "o texto literário é mais do que produzir ou representar as relações sociais, interessa à literatura produzir efeitos que levem o público leitor a participar, a atuar na transformação da realidade".

Zilberman (2008, p. 17), por sua vez, enfatiza sobre os efeitos da literatura no leitor:

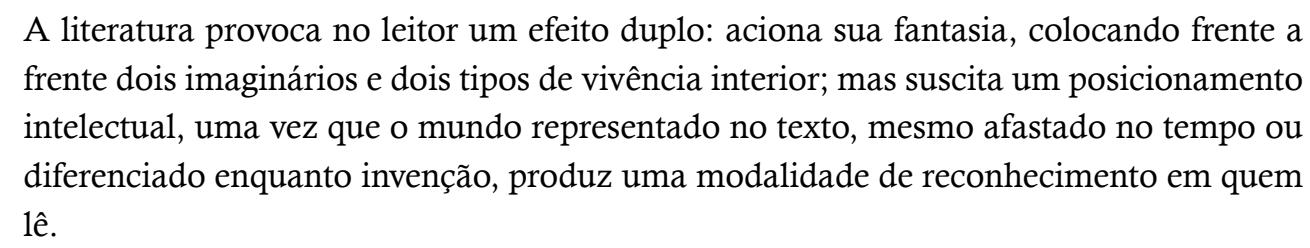

Atividades como rodas de leitura, leitura pública, mostra literária, feiras de livros indicações literárias, formações e palestras para professores, exibição de vídeos de literatura são exemplos de atividades com as quais busca-se promover a leitura de literatura, a curiosidade, o contato e a apropriação da cultura literária de produção internacional, nacional, regional e local, tornando compreensível que leitura, literatura e conhecimento é, antes de tudo, um direito.

\begin{abstract}
Promover a leitura só tem sentido enquanto movimento político de contrapoder, enquanto parte de um programa de democratização. A questão que se coloca é a do direito de ler e não da promoção deste ou daquele comportamento ou a valorização de tal ou qual gosto. O que interessa não é o que um sujeito lê, se gosta mais disso ou daquilo, se encontra ou não prazer na leitura, mas sim se poder ler e lê o quê, quando e quanto quiser. (BRITTO, 2015a, p.141)
\end{abstract}

Quando se refere ao direito à leitura, à democratização da literatura, está se questionando o acesso aos clássicos, a arte, a variedade literária, enfim ao conhecimento humano acumulado durante séculos, pois, só tendo conhecimento de modo amplo é que um leitor conseguirá fazer relações, entender e sentir o prazer e a liberdade que a literatura e a arte proporcionam.

A literatura é um elemento essencial da cultura e, tendo caráter extremamente civilizatório, humanizador, possibilita às pessoas maiores e fundamentais condições de participação na ordem da vida, da dimensão fundamental da existência de forma ampla. (SANTOS, 2016, p.23)

As experiências com os textos literários proporcionam apreciação estética, alargamento de conhecimentos e repertório cultural, desperta em nós as características importantes à formação. Quando se proporcionam experiências com textos literários, possibilitam-se formas de expansão da realidade, da imaginação, da linguagem e a criação, características essenciais ao desenvolvimento humano. Machado (2012, p.53), esclarece sobre a experiência desde cedo com os textos literários: "a leitura literária, quando bem trabalhada desde a infância, desencadeia processos criativos que passam a oferecer compreensões simbólicas e ajudam a dar sentido à existência".

Em algumas regiões da Amazônia este processo de formação leitora, também pode contribuir para autoafirmação ${ }^{2}$ de identidade de muitos povos, possibilitando maior reflexão sobre suas histórias, origens, o percurso de violência sofrido, exploração e "tentativa" de apagamento das suas culturas. Há inúmeros trabalhos e registros históricos, estrangeiros, nacionais e regionais sobre os povos da Amazônia que falam sobre sua gente, flora, pajelanças, fauna e ensinam sobre o modo de ser daqui para os de lá. Entretanto, na maioria das vezes, a população desco-

2 Atualmente, muitas aldeias na região do Arapiuns e Tapajós estão em fase de reconhecimento de seus territórios. Muitas aldeias encontram-se em estudos antropológicos ou homologação e outras já estão com seus territórios demarcados. A aldeia Nova Vista encontra-se em reconhecimento do território pela Funai. 
nhece essa produção. A falta do acesso à tecnologia do ler, impede de conhecer não apenas as produções que os descrevem, como também a cultura do outro povo que vive na outra margem do rio, além disso, impede de conhecer que o seu imaginário: mitos, lendas, contos, causos, servem de matéria prima para a produção de clássicos literários, o homem da Amazônia só pode acessar estas cosmogonias, em sua forma mais ampla, através do ato de ler.

Santos (2016), em sua tese de doutorado, desenvolveu uma pesquisa sobre leitura em "lugares distantes" e as possibilidades e desafios do incentivo à leitura no cenário amazônico. Para ele:

Trabalhar a leitura tendo como fim a construção de sentidos perpassa, portanto, a conscientização do homem da sua situação de existir em um espaço onde reina a desigualdade social. Assim, formar leitores com o domínio da contrapalavra é subversão ao sistema, já que passarão a indagar constantemente sobre as condições e possibilidades sociais de ser leitor dentro de um sistema excludente. (SANTOS, 2016, p.33)

Desta maneira, a criação de uma biblioteca é o ponto de partida para consolidar o contato com a leitura, literatura e principalmente a ampliação da cultura local, além de esclarecimento sobre direitos básicos. Entretanto, a realidade concreta do lugar e a nítida ausência do Estado são barreiras monumentais desafiadoras.

\section{Biblotecas: espaÇOS DE FORMAÇão}

A palavra biblioteca tem origem nos termos gregos biblion (livro) e theka (caixa), significando o móvel ou lugar onde se guardam livros. Historicamente as bibliotecas tinham a função de organizar e preservar o conhecimento humano, porém, com o advento da tecnologia, novos formatos de bibliotecas foram surgindo, entre estes, as bibliotecas on-line, como a Biblioteca Digital do Museu Nacional.

Dos elementos que caracterizam uma biblioteca física: livros, cadeiras, mesas, estantes, prateleiras, a organização e caracterização da biblioteca, são condições fundamentais para a efetivação e difusão de leitura, conhecimento e informação. Para Silva e Silva (2010, p. 205), biblioteca é "um espaço de cunho físico ou virtual que promove as noções de organização, disseminação e acesso à informação através de instrumentos tecnológicos diversos, seja manual, seja eletrônico". Esse espaço deve ser compreendido conforme apontamentos de Britto (2015b, p. 17), "como possibilidade objetiva de produção e disseminação da cultura e do conhecimento, de formação intelectual e política, de experimentação estética e afirmação subjetiva".

Entender o papel das bibliotecas vai além da concepção de montes de livros, estantes, prateleiras ou de empréstimos e devoluções: "não é qualquer espaço com livros e estantes que deve-se ser considerado biblioteca" (SILVA; SILVA, 2010). Esses espaços devem-se ser compreendidos como fundamentais para disseminação de cultura e conhecimento, na biblioteca circulam mais que literatura, na biblioteca circulam um conjunto de obras que contribuem para o conhecimento da produção intelectual humana em diferentes níveis de complexidades, isso inclui: a filosofia, a sociologia, a religião, a história, a psicologia e a arte como elementos fundamentais. Portanto, a ideia da biblioteca não deve estar vinculada especificamente a literatura para maravilhamento.

Sabendo da relevância desse espaço, com possibilidade de impactar pessoas e lugares, principalmente os mais afastados, cabe uma reflexão em torno do seguinte questionamento: se a 
biblioteca têm múltiplas funções, infinitas formas de gerar conhecimento, o que leva cada vez mais espaços como esses permanecerem fechados ou vão a ruína em tão pouco tempo ou, mais comum, não existirem?

Primeiramente para que se compreenda o papel da biblioteca para escola, comunidade ou na vida das pessoas é necessário que este espaço faça sentido: "A grande maioria da população, por não ver traduzidos seus anseios cotidianos na biblioteca, não a visualiza como uma instituição socialmente útil" (SILVA; SILVA,2010, p.210). As bibliotecas, especialmente as públicas, tenderam por muito tempo a se estruturar em função dos interesses da classe dominante como se verifica em sua na própria forma de organização, limitada ao público que domina a escrita,

$\mathrm{E}$, ainda que aberta a todos, suas decisões e formas de organização se fizeram, por um longo período, somente para as pessoas inseridas na cultura escrita. A maioria das pessoas - por falta de instrução, de identidade ou até pela dificuldade objetiva de acesso - não se incluía (e ainda não se inclui) no público usuário. (BRITTO, 2015b, p.41)

Para uma grande parte da população livros e leitura são sacralizados, e isso ocorre devido à distância que o trabalhador coloca entre si e o conhecimento; o ócio, o pequeno intervalo entre uma jornada e outra ao fim do dia, é o único alívio de um corpo explorado. Para o corpo cansado, preocupado e, quiçá, faminto de alimento, de esperança, ler não é uma prioridade.

A ausência de bibliotecas é fator predominante, especificamente na região Oeste do Pará, Município de Santarém, região Arapiuns (o sentido de biblioteca aqui engloba: estrutura, organização e disseminação, e não apenas um cantinho de leitura com revistas rasgadas para entretimento de crianças). São poucas as comunidades que têm acesso a esse espaço de conhecimento, e quando o tem, foi implantado de maneira indireta, alguns, por projetos de caridade, o que acaba desvinculando do sentido de direito, formação, emancipação, ao contrário acabam legitimando um sistema opressor e excludente. Em sua grande maioria, esses "projetos sociais" são feitos por um agente externo, OGNs, grupos religiosos, que adentram a Amazônia e acreditam estarem fazendo um "favor".

\footnotetext{
A leitura não pode ser confundida com propaganda - quando se pretende, por interesse comercial, incutir no outro o desejo a sensação de consumir algo- nem como benevolência ou a solidariedade- quando almeja minimizar sofrimentos e carências-nem com proselitismo religioso ou político- quando se busca a adesão da pessoa a uma crença (e seus hábitos de valores) ou a um partido [...] a leitura demanda engajamento em práticas de leitura de textos literários e de expressão cultural que instigam a indagação (BRITTO, 2015b, p.33).
}

Importante mencionar que o que está se criticando não é a promoção da leitura ou a realização de tal ato, mas a concepção com que determinada ação se consolida e todo o pano de fundo que dificilmente é compreendido pela comunidade local, que hipnotizada pela novidade acata. O que se sublinha é que essas campanhas e projetos não impulsionam a população a refletir, inclusive, de saber o que lhes é de direito. Silva e Silva (2010, p. 207) menciona sobre a necessidade do diálogo e criação de vínculos com a comunidade a qual a biblioteca será instalada:

Para uma efetiva atuação da biblioteca é preciso que esteja em sintonia com as comunidades que estão inseridas em suas ações. Mas antes de inserir uma biblioteca num determinado local é preciso estudar aquela comunidade, perceber suas carências e qualidades, de modo a buscar suprir e aprimorar informacionalmente a realidade da comunidade escolhida. 
Ações de leitura, implantação de bibliotecas exigem construção coletiva, compreensão da função da biblioteca e dos serviços que ela dispõe, entendendo-a como lugar de formação, de discussão e produção de conhecimento.

\section{Metodologia: Os desafios e as Perspectivas da Pesquisa-ação na aldeia Nova VISTA}

A aldeia Nova Vista território do povo Arapiun $^{3}$, está localizada à margem esquerda da região Arapiuns. Na aldeia vivem cerca de 60 famílias e uma média de 230 pessoas que desenvolvem basicamente a produção agrícola familiar: produção de farinha de mandioca, criação de pequenos animais, pesca, caça e extrativismo florestal. Na aldeia Nova Vista, assim como na região Arapiuns, fala-se a Língua Portuguesa, não por opção - mas resultado de um processo de colonização que provocou profundas transformações culturais, dentre essas, o apagamento de inúmeras línguas nessa região. Há proximidade constante com centros urbanos, embora essa relação seja tensa e conflituosa, considerando que o lugar tem especificidades culturais, ainda assim, os indígenas dessa região transitam entre cidade e aldeia constantemente.

A atual pesquisa é continuação de um trabalho iniciado em 2016, ainda no período de graduação, que investigou os desafios e as possibilidades de instituir uma biblioteca na aldeia Nova Vista. Com a implantação e funcionamento da biblioteca, inaugurada no dia 20 de abril de 2018, contando com aproximadamente setecentos exemplares no seu acervo, incluindo clássicos da literatura regional, nacional, internacional e etc. Tornou-se necessário compreender os efeitos e transformações produzidos por meio das novas dimensões culturais induzidas pela biblioteca na aldeia. Para entender esse processo, colocou-se como questionamento central: "Quais as possibilidades de formação em "lugares distantes" e como tornar a biblioteca um espaço de formação e circulação de conhecimento?"

O foco foi no coletivo como possibilidade de transformação daquela realidade leitora, tanto para a compreensão da biblioteca como espaço de conhecimento, estudo e formação de toda aldeia, isto é, a existência, manutenção e pleno funcionamento depende da coletividade, daí a importância da participação de toda comunidade nas ações de ler. Utilizou-se neste estudo a pesquisa-ação (FRANCO, 2005;2010;2016), o que configura como uma pesquisa-ação crítica, pois, possui características formativo-emancipatório. É formativa, "pois o sujeito deve tomar consciência das transformações que vão ocorrendo em si próprio e no processo". É emancipatória, "pois mediante a participação de sujeitos conscientes passam a ter oportunidade de se libertar de mitos e preconceitos que organizam suas defesas à mudança e reorganizam a sua autoconcepção de sujeitos históricos." (FRANCO, 2005, p.486)

Quando aventada a possibilidade de, por meio da pesquisa-ação, instituir um lugar de ler com os moradores e não para os moradores, foi necessária a compreensão do tipo de trabalho que estávamos prestes a desenvolver, os processos que buscaríamos construir com a comunidade e o tempo que teríamos para a pesquisa. A imersão e apropriação desta metodologia se consolidou em uma pesquisa complexa e com muitas indagações.

Para Franco (2016), "criar um universo cultural coletivo é uma tarefa fundamental do pesquisador em pesquisa-ação; no entanto, precisa fazê-lo na perspectiva de construção coletiva, de buscar participação, permitindo a contribuição de todos" (p.516). Diferentemente de outras

3 Neste trabalho será utilizada a grafia Arapiun, por orientação da professora de Nheengatu da escola Nossa Senhora de Fátima da aldeia Nova Vista. 
pesquisas, que contam com um agente externo, nesta, o agente está inserido no contexto pesquisado, desempenhando duplo papel, de participante/moradora e pesquisadora. A flexibilidade de papéis deve ser dividida com os participantes da pesquisa para que sejam coautores. Para isso, se fez necessário um cronograma de reuniões e encontros, para discutir sobre o projeto e criar estratégias de organizar a intervenção.

Para a investigação, primeiramente, foi realizado um encontro com comunitários e equipe escolar para 'diagnosticar', procurar estratégias pedagógicas, sugestões de elaboração de um plano de intervenção e, principalmente, averiguar o "problema", as possibilidades de mudança com relação à prática da leitura naquele lugar. Foi realizado levantamento de informações, incluindo: a utilização da biblioteca desde sua inauguração: as contribuições, as dificuldades, organização e manutenção do espaço de ler; incentivo e frequência dos usuários.

Após esse encontro, organizaram-se todas as sugestões indicadas na reunião em um plano de intervenção que iniciou em outubro de 2018. O terceiro momento consistia/consistiu na reflexão, avaliação e reformulação contínua das estratégias de leitura.

O projeto de intervenção A leitura que nos aproxima, a literatura que nos transforma faz parte do Projeto de Pesquisa Leitura e formação: contribuições da biblioteca no rio Arapiuns-aldeia Nova Vista. O objetivo da intervenção era desenvolver ações que movimentassem a biblioteca, proporcionando aos moradores e o público escolar atividades que possibilitassem a experiência de ler, principalmente textos literários.

No mês de setembro de 2018 o projeto de intervenção e o cronograma foram apresentados à aldeia, sendo também estabelecidas as datas de realização das atividades de leitura, para não coincidirem com outras ações. As atividades de intervenção se adaptaram à programação da comunidade e ao calendário letivo determinado pela Secretaria Municipal de Educação de Santarém.

Mesmo com a adaptação, o cronograma era flexível, pois, era necessária toda uma logística para ir mensalmente a aldeia, além disso, tinha de ser considerado a vinda mensal de professores para cidade, inclusive, alguns estavam concluindo seus cursos superiores. Ademais, era importante manter contato direto com as lideranças da comunidade e escola, no caso de reuniões comunitárias e eventos que pudessem coincidir com o cronograma, as atividades de leitura eram remarcadas. Por vezes, alguns professores não estavam presentes nas ações, mas sempre justificavam, quanto as crianças, independente do dia das ações, sempre compareciam em grande número.

\section{Resultados: “Os efeitos de LeVAR A LER"}

Com o desenvolvimento desse trabalho, que já somam quase três anos é possível fazer alguns apontamentos acerca dos efeitos de levar a ler na aldeia Nova Vista. As conclusões que apresento são baseadas nas observações durante a pesquisa, no diário de campo, registros fotográficos, conversas informais e atividades realizadas no período de intervenção. Serão consideradas as observações sobre os efeitos em torno dos livros; a circulação da leitura; participação da aldeia, isto é, "os modos de ser", como a aldeia passou a se organizar em torno dessas ações leiturizantes.

Buscou-se compreender os modos de sociabilidade, os compromissos que as pessoas assumem, as relações de cultura e das atitudes. É necessário adiantar sobre os dilemas e limites que se 
encontram nesse lugar distante, as contradições objetivas da vida real, que inclusive restringem tanto as possibilidades de uso da biblioteca, quanto as compreensões das obras que se propõem.

É importante mencionar o sucesso das atividades. Avalio-as positivamente, houve forte participação da comunidade escolar, que mensalmente encontravam-se para ler, ouvir, ver imagens e apreciar literatura. As atividades de leitura aconteceram de forma gradual; iniciamos com a leitura pública de contos, crônicas, poemas, fábulas, os primeiros textos não eram longos, priorizamos a apreciação da escuta dos textos, era impressionante como as crianças permaneciam atentas ao que líamos. Posteriormente, foram inclusas nas rodas de leitura algumas discussões; se, no começo, havia timidez dos estudantes para fazer a leitura e comentários, com o passar dos meses a desenvoltura, os pontos de vista e as intertextualidades avançaram. A seguir trago um exemplo das discussões que fazíamos após as leituras.

No mês de maio de 2019, foram lidos contos indígenas e africanos nas rodas de leitura.
Um dos contos africanos "O acordo entre o leão e o homem" despertou bastante o inte-
resse das crianças e adolescentes ali presentes. Ao terminarmos a leitura, começamos a
conversar sobre o texto. Uma adolescente comparou o acordo narrado entre o homem
e o leão, que era recheado de más intenções, com a política, neste caso, ela se referia ao
agente político e aos inúmeros acordos que deixam de cumprir com a população, além
do mais, é provável que ela tenha associado a esperteza daqueles que pleiteiam um cargo
político e fazem promessas que não são cumpridas após se elegerem. (Diário de campo,
maio de 2019)

Aproximo as observações realizadas sobre os efeitos da leitura em lugares distantes, com o que Santos (2016, p. 147) analisa:

Foi possível ocorrer nesses lugares distantes a descoberta de novos conhecimentos com a leitura dos livros de literatura que oportunizaram a professores e alunos chegar à conclusão de que a leitura deles também é conhecimento de qualidade. Provaram de um tipo de leitura diferente, que foi o exercício de ler um texto de literatura e saber que os significados não estão na superfície, mas nas camadas profundas. Assim, cada vez que o leitor teve o poder de mergulhar mais e mais nas profundezas do texto, mais significados brotaram da tessitura textual que passaram a significar o mundo.

No público infantil é mais perceptível os efeitos das ações de ler, principalmente por movimentarem diariamente a biblioteca, sendo os usuários mais frequentes, os alunos do fundamental I e II. Ademais, observei crescimento progressivo de melhorias da leitura pública dos estudantes, no sarau literário ficou explícita a desenvoltura dos alunos, especialmente das séries iniciais (é evidente que isso é resultado não apenas das ações de leitura, mas de atividades organizadas pelos professores).

Durante todo o período de pesquisa foi possível observar que crianças e jovens leem, e leem bastante. É evidente que, para que a leitura se constitua como exercício contínuo, é preciso que se criem formas e atividades sistematizadas que estreitem a relação estudantes, livros e leitura, sendo essa literária ou outra. Além disso, a realidade concreta da maioria dos jovens é uma barreira firme para que seja superada, sendo essencial a articulação entre escola e família.

Após a organização da biblioteca e as atividades de leitura, a procura por livros aumentou significativamente. Se anteriormente não era possível ver alunos lendo de forma constante, e é provável que a falta de organização da biblioteca contribuísse para isso, atualmente, com melhorias no acervo e na estrutura (mínimas), é outra a realidade. A biblioteca é o lugar mais 
movimentado da escola, as crianças mantêm frequência assídua, atentas às novidades, que desaparecem pouquíssimo tempo após serem colocadas nas prateleiras. Observei que a estrutura influencia crianças e jovens a permanecerem mais tempo na biblioteca para ler, estudar, pesquisar, isto é, um lugar bem organizado, com uma boa oferta de livros também leva a ler.

A autonomia dos professores em relação as práticas de leitura foi ocorrendo de forma gradual, os docentes demonstraram disponibilidade de participar e pensar as ações de intervenção. Alguns, no decorrer do ano passaram a assumir atividades de leitura para além do planejado. Como estruturamos um cronograma, já sabiam previamente as atividades e, dessa forma, trabalhavam os gêneros antecipadamente.

Como havia um cronograma organizado, os professores buscavam trabalhar anteriormente as práticas de leitura. Uma das professoras enfatizou que vinha trabalhando poemas e parlendas anterior a atividade que ainda aconteceria. (Diário de campo, março de 2019).

Considero um desafio, um dos mais complexos, constituir uma pesquisa de forma coletiva, na qual haveria de aprender a ser pesquisadora e, ao mesmo tempo, respeitar as demais pessoas, produzindo conhecimentos com os professores, e não para eles. Mas, como torná-los participantes ativos? Primeiramente, optei por escutá-los, respeitando suas sugestões, acatando as críticas, problematizando a realidade, a fim de instigá-los a encontrar alternativas para se sentirem parte integral do processo (FRANCO, 2016).

A mudança na postura de alguns docentes pode ser reflexo das ações desenvolvidas na aldeia, porém, é imprescindível os professores terem formação continuada, principalmente pela especificidade do modelo de educação no qual a escola está inserida, que é a educação escolar indígena. Os professores da escola Nossa Senhora de Fátima são oriundos de uma formação aligeirada na região Oeste do Pará.

Apesar de o Oeste do Pará estar afastado dos grandes centros urbanos, o poder econômico também dita a vida do homem dessa região, espoliando as riquezas naturais e alinhando a existência das pessoas à nova ordem mundial. A força do capital obriga o Estado a formar os professores aligeiradamente, desconectados dos bens culturais de primeira ordem. Também são desconhecedores de parte dos aspectos culturais produzidos pela sociedade da sua própria região, por sua vez, após essa instrução rarefeita, os professores passam a formar as novas massas consumidoras, certamente, este é o ponto crucial que limita o levar a ler no Oeste do Pará. (SANTOS, 2016, p.146)

A relação constituída ao longo desses anos oscilava bastante, ao final tínhamos não apenas professores, mas todos os funcionários colaborando nas atividades de intervenção, acima de tudo, havia reciprocidade de respeito. As atividades finais foram planejadas e discutidas entre todos nós, mas o trabalho de base foi organizado rigorosamente por eles. É arriscado afirmar que houve transformação coletiva, principalmente porque todo processo de transformação é longo, lento e, por vezes, aparece individualmente em cada professor. Para isso, teríamos de ter dedicado uma investigação em torno dessa questão. Da mesma forma com os moradores e crianças: só poderemos mensurar quão profunda foi essa transformação daqui a anos.

No entanto, posso apontar os efeitos das ações, reuniões, leituras e o conhecimento compartilhado, das formações, das problematizações e buscas de alternativas para melhorar a circulação do conhecimento. Uns dos efeitos mais relevantes observado foi: alguns docentes passa- 
ram a refletir e a falar, inclusive em reuniões, sobre a secundarização das atividades escolares em prol de outras dentro aldeia, como torneios e festas; questionaram a falta de debate e desatualização do Projeto Político Pedagógico da escola; refletiram sobre o estreitamento com os pais para melhorar o espaço da biblioteca, concluindo que este assunto está muito restrito à escola. Enfim, os funcionários da escola demonstraram comprometimento e participação nas ações de leitura, ainda que parcialmente, demonstrando, inclusive, interesse sobre que será feito nos anos seguintes.

Em contraste, nenhum professor aderiu ao trabalho voluntário na biblioteca, persiste entre os docentes a opinião da necessidade de haver um funcionário exclusivo para a biblioteca - é válida a necessidade de um funcionário para esse espaço, mas isso não implica na não contribuição de cada professor para mantê-lo organizado. Durante todo o tempo de pesquisa, a organização da biblioteca foi realizada por mim e, em curto período, pela pessoa vinculada ao Programa Mais Educação (Programa do Ministério da Educação que propunha ampliação da jornada escolar de crianças e adolescentes do Ensino Fundamental para melhorar a aprendizagem em Língua Portuguesa e Matemática.). Alguns professores não acompanhavam as crianças na biblioteca, gerando desorganização e ocasionando perdas do acervo por falta de registro e acompanhamento do empréstimo.

Partindo do princípio de que ler é um direito (BRITTO, 2015a; CASTRILLÓN, 2011a), não há como vincular que o que vem se constituindo na aldeia com a biblioteca e as atividades de leitura seja confundido com assistencialismo ou caridade Ainda assim, é possível analisar que esse pensamento é muito forte na aldeia, implicando desde o princípio desse trabalho a necessidade de descontruir a ideia de fazer para comunidade, e pôr em seu lugar a ideia de fazer com a comunidade. Por isso, a participação tímida e indireta dos moradores (mas como plateia das ações que agentes) nas atividades inquieta, principalmente por conta da comunidade ser pequena, na qual circula informações rapidamente.

Essa questão demandou autocrítica ao concluir as ações de intervenção, ao focar estritamente no público escolar. Não atentei à importância da informação circular na aldeia, seja com informativos, cartazes ou qualquer outro meio, o que significaria um convite para a ação, esperei pela atitude dos moradores.

A escola é o único local em que circula o conhecimento formal na aldeia, juntamente com a biblioteca que é onde está organizado materialmente esse conhecimento, porém a biblioteca funciona de forma improvisada na sala dos professores, não há na planta da escola um lugar para a biblioteca. É válido observar, contudo, que o plano de construir um lugar apropriado vem sendo amadurecido e está agendada uma discussão sobre este assunto no decorrer do ano letivo de 2020, com as lideranças locais e comunitários.

Diante do exposto, as experiências da aldeia Nova Vista e a constituição de uma biblioteca, serviu de ponto de reflexão para que a aldeia Murucy, localizada nas proximidades e parte do mesmo território indígena, iniciasse a construção de uma biblioteca conjuntamente com o grupo de pesquisa Lelit.

É importante mencionar a despreocupação do poder público, durante todo o processo de organização da biblioteca. Mesmo sabendo da realidade - foram comunicados através de ofícios -, não houve suporte da secretaria, com exceção de algumas caixas de livros do Pacto Nacional pela Alfabetização na Idade Certa (Pnaic). Atualmente, há a demanda para que a Secretaria de 
Educação do Município contrate um funcionário para a biblioteca; porém, não há previsão e, com a atual conjuntura da educação e sem uma gestão escolar que privilegie os interesses coletivos, dificilmente avançaremos.

\section{CONSIDERAÇÕES FINAIS}

Nesta parte da Amazônia, problemas básicos de saúde, comunicação e educação não foram superados. Muitas aldeias não têm posto de saúde, não há energia elétrica (usam-se geradores), as escolas não têm salas para todas as turmas e há lugares que nem prédio próprio têm. No entanto, há realidades ainda mais complexas, relacionados ao abandono e desrespeito, principalmente com saúde e educação, de modo que, a distância mais significativa não é a geográfica, mas a do Estado.

Os problemas com a promoção e circulação da leitura e conhecimento estão entrelaçados a problemas sociais e culturais, resultados de um processo histórico de exploração e desigualdade. Desta forma, para compreender a leitura na aldeia, é necessário considerar o contexto social e cultural desse lugar e dos lugares afins, nos quais se estabelecem uma ordem de prioridades emergenciais (e que não deixam de ser).

Alguns dos efeitos apontados neste artigo estão: circulação de leitura e livros na aldeia desde a organização da biblioteca (2018); aumento nos empréstimos de livros, especialmente literários, o que podemos afirmar claramente que as crianças e jovens da aldeia Nova Vista têm frequentado bastante a biblioteca desde sua implementação; as ações de leitura desenvolvidas através do projeto de intervenção, juntamente com outras atividades de leitura realizada por alguns professores, contribuem para aperfeiçoamento da leitura dos estudantes; a participação dos moradores, ainda que tímida deve ser considerada; previsão de construção um lugar próprio para biblioteca.

Pretendo seguir investigando as ressonâncias da leitura de forma efetiva, ao entender que o público de usuários em sua grande maioria são crianças e adolescentes, compreende-se a necessidade de continuação das práticas de leitura e acompanhamento, isso implica longos anos de pesquisa.

Importante lembrar que, melhorar as condições de leitura não significa melhorar as desigualdades sociais, assim como o livro não pode ser visto como objeto sagrado capaz de curar os males do mundo. Contudo, a biblioteca e o conhecimento dela, nada mais é que um direito, um bem cultural que pode possibilitar aos moradores da aldeia Nova Vista mais formação intelectual, social, cultural e política.

\section{READING AND EDUCATION: CONTRIBUTIONS FROM THE LIBRARY IN ARAPIUNS RIVER - NOVA VISTA VILLAGE}

\footnotetext{
ABSTRACT: This article reports an action research that aimed to investigate how the circulation of reading happens, and whether it occurs in a participatory way or not, among the citizens of an indigenous community. The methodology is based on Franco (2005; 2010; 2016), and the cyclical spirals: planning; action; reflection, which make it possible to reformulate the actions whenever necessary, analyzing the object and the research process continuously. The following are used as theoretical anchors: Britto (2003, 2015a, 2015b); Candido (2011); Santos (2016); Saviani and Duarte (2010). The results show that there is a significant circulation of reading and books in the village from the school's library organization; reading actions have contributed to the improvement of students' reading.
} 
However, community participation is still timid and indirect, as well as part of the university faculty, in short, people in the community still do not take over the library in its entirety.

KEYWORDS: Education. Reading. Literature. Library. Indigenous

\section{REFERÊNCIAS}

BRITTO, Luiz Percival Leme. Contra o consenso: cultura escrita, educação e participação. Campinas: Mercado de Letras, 2003.

Ao revés do avesso - Leitura e formação. São Paulo: Pulo do Gato, 2015a. 144p.

No lugar da leitura - Biblioteca e formação [recurso eletrônico]; Rio de Janeiro: Edições Brasil Literário, 2015b.

CANDIDO, Antonio. A literatura como direito. In: Vários escritos. São Paulo: Duas Cidades, 2004. p. 169-191.

CASTRILLÓN, Silvia. O direito de ler e escrever. São Paulo: Pulo do Gato, 2011a.

Escola, leitura e escrita: a necessidade de um olhar externo. Revista Emília, nov. 2011b. Disponível em: https://revistaemilia.com.br/escola-leitura-e-escrita-a-necessidade-de-um-olharexterno/. Acesso em: 22 de março de 2019.

COLOMER, Teresa. Andar entre livros: A leitura literária na escola. São Paulo: Global, 2007.

DUARTE, Newton. Os conteúdos escolares e a ressurreição dos mortos: contribuição à teoria históricocrítica do currículo. Campinas: Autores Associados, 2016.

FRANCO, Maria Amélia Santoro. Pedagogia da pesquisa-ação. Educação e Pesquisa, 2005. v. 31, n. 3, p. $483-502$.

Pesquisa-ação: a produção partilhada de conhecimento. Ensino, Educação e Ciências

Humanas, 2010.v. 11, n.1, p.05-14.

Pesquisa ação-pedagógica: práticas de empoderamento e participação. Educação Temática

Digital, 2016.v.18, n.2, p. 511-530.

FREIRE, Paulo. Ação cultural para a liberdade. Rio de Janeiro: Paz e Terra, 1976.

FRIGOTTO, Gaudêncio. Educação Omnilateral. In: SALETE, R.; PEREIRA, I. B.; ALENTEJANO, P.; FRIGOTTO, G. (orgs). Dicionário da educação do campo. Rio de Janeiro, São Paulo: Escola Politécnica Joaquim Venâncio, Expressão Popular, 2012, p.267-274

MACHADO, Maria Zélia Versiani. A criança e a leitura literária: livros, espaços, mediações. Curitiba: Positivo, 2012.

NUNES, Benedito. Ética e Leitura. In: BARZOTTO, V. H. (org). Estado de Leitura. Campinas: Mercado de Letras, 2009, p. 193-215.

SANTOS, Zair Henrique. Entre o compromisso e a realidade: Relato e análise de uma ação de levar a ler no Oeste do Pará. Tese de Doutorado. Faculdade de Educação - Unicamp. Campinas, 2016.

SAVIANI, Dermeval; DUARTE, Newton. A formação humana na perspectiva histórico-ontológica. Revista Brasileira de Educação, v. 15 n. 45, p. 422-590, set. /dez. 2010.

SILVA, Ezequiel Theodoro. De olhos abertos: Reflexões sobre o desenvolvimento da leitura no Brasil. São Paulo: Ática, 1991.

Leitura na escola e na biblioteca. São Paulo: Ática, 2005

SILVA, Jonathas Luiz Carvalho; SILVA, Roosewelt Lins. Biblioteca, luta de classes e o posicionamento da Biblioteconomia brasileira: algumas considerações. Em Questão UFRGS, v. 16, p. 203-217, 2010.

ZILBERMAN, Regina. Sociedade e Democratização da Leitura. Porto Alegre: Mercado Aberto, 1983.

O papel da literatura na escola. Via Atlântica, n. 14, p. 11-22, Dez/2008. 